\title{
Editoral
}

\section{Revisiting the surveillance camera revolution: Issues of governance and public policy. Introduction to part one of the Special}

\section{Issue}

Video surveillance cameras and systems - commonly referred to as Closed-Circuit Television (CCTV) are a defining feature of modern society. Their widespread use, as fixed or mobile devices, deployed for a range of purposes and by a variety of public and private actors, is now unsurprising and generally accepted in most countries. The normality of these surveillance practices, and the technologies used, are a world away from the early tube cameras used for local broadcasting and the isolated monitoring of industrial processing in the 1930s and 1940s. The diffusion processes, which have led to the exponential growth of these cameras and systems, have included evolutions in the design, function and capabilities of systems, especially around opportunities for extended, combined and automated systems offered by new information and communication technologies. These technologies have been shaped by a raft of interested parties, including engineers, manufacturers, clients/service users, politicians and regulators. The changing and contested terminology used to denote and describe the socio-technical practices around these systems illustrates both the variety of applications and their wider social and political context. 'Video surveillance', 'video observation', 'video protection' and 'visual surveillance' share the semantic reference to viewing and imply monitoring rooted in the technological practices of optoelectronics, but they convey different meanings about the benefits and uses of technology. In the same way, terms like 'spy cameras', 'big brother cameras', 'security cameras' and 'public safety cameras' convey different meanings and different perceived 'impacts'. An example of the political significance of language and terminology is provided by the French Government, which decided to replace the term 'video surveillance' with 'video protection' in all legal texts and regulations in an attempt to influence the perceived societal 'meaning' of these systems (see Heilmann in this Special Issue).

Broader academic interest in video surveillance followed the proliferation of CCTV cameras and practices in a wide range of public and private settings in the mid- to late- 1990s. The most rapid and spectacular diffusion of public space CCTV is often attributed to the United Kingdom, where the installation of new camera schemes was supported by central government funds and operational advice, as well as political rhetoric to assist in the 'fight against crime'. This was not the first time that government activity had led to the deployment of CCTV cameras, they had previously been used in a range of discreet settings, including banks, car parks and motorways. But it was the widespread deployment of these systems in 'public places', including residential areas, and where ordinary citizens and service users became routinely surveyed by the state, that so much academic interest was generated. 
The British experience, which signalled the 'surveillance camera revolution', has become the point of reference for studying video surveillance in the social sciences. The emergent academic studies and discourses that have sought to comprehend this 'revolution' have been dominated by perspectives emanating from law, criminology, sociology and geography. Legal scholars have discussed novel regulatory approaches designed to address issues relating to privacy and data protection. Criminologists have sought to understand the effects of CCTV on crime, the perceptions of crime and on disorder, antisocial and other behaviour deemed undesirable. Sociologists have located the rise of public space CCTV in wider global trends and the emergence of 'late capitalism', in which the shift from industrial societies struggling with the distribution of the fruits of technological progress to societies mainly concerned with services and the calculation and management of risks has led to a new context and the rise of a 'new penology', including techniques for crime prevention like CCTV. Geographers and urban scholars point to the economic transformation of cities and towns and the emergence of 'urban entrepreneurialism' as the driving force behind attempts to promote central areas as places of consumption. These were to be rendered safe and attractive for customers by means of surveillance cameras directed against any nuisance, including 'undesirable' persons and behaviour. Alongside the grand narratives about surveillance in society has been a trend for descriptive studies of specific cases. Typically, these are intended to highlight the use of CCTV in a specific setting or to calculate a systems 'impact' on levels of crime and disorder. Additionally, there has been a series of ethnographic studies where the surveyors and the surveyed have been observed and asked about their experiences and attitudes. Although often descriptive, these micro-studies have started to show the significance of context and the institutional settings in which cameras are deployed, as well as their importance as explanatory factors in how video surveillance works, is used, and how it is integrated into the broader polity.

In relation to video surveillance, issues of governance and public policy are rarely explicitly addressed by social scientists. This two-part Special Issue aims to fill this gap. It brings a focus to the ways in which the implementation of cameras and systems, and their operational and technical features, are the product of decisions and policies made in a variety of contexts and by a variety of authorities and interested parties. This line of argument suggests that the surveillance camera revolution must not be understood as just a technological phenomenon, and that the context in which the cameras are deployed shapes their diffusion and use. If we follow this line of argument, it is easier to understand why one country may encourage the use of surveillance cameras, but for historical and cultural reasons, another may choose to limit their use. Equally, one country may have a strong tradition of legislation and regulation, whilst another may lean towards voluntary or self-regulation. Understanding the contextual environment surrounding the deployment of video cameras, including public attitudes toward surveillance, mass-media representations of the systems, and beliefs about the capabilities of technology, is critical to understanding why video surveillance cameras have diffused so widely in society, and how they are currently used. With this in mind, this two-part Special Issue aims to revisit the 'surveillance camera revolution', to present some contemporary thinking and research on the use of CCTV, and to draw out issues relating to governance and public policy.

The use of video surveillance cameras and systems in public places in modern society raises a range of issues relevant to governance and public policy, both in terms of the regulation of new technologies and also about relations between citizens and the state. The deployment of these systems is naturally of interest to governments because they are concerned with influencing, or controlling, the behaviour of citizens. As such, surveillance cameras embody a power relationship between the surveyor and the surveyed. Because surveillance cameras are intrinsically powerful, their use by public agencies for the 'public interest' is perceived to be acceptable, especially when subject to democratic and regulatory 
control. In Switzerland, for example, recent police CCTV projects, in St.Gallen, Lucerne and Renens, have been subject to a public vote, thereby increasing opportunities for democratic debate and scrutiny. In this case, public participation in the decision making processes has contributed to further legitimize and publicize the deployed systems. If we take a governance or public policy perspective of the widespread diffusion of surveillance cameras, then issues about who shapes the public policy-making process, who benefits from diffusion, and how the cameras are used and regulated, come to the fore. What has been remarkable about the surveillance camera revolution is not just the speed of diffusion, but also that this diffusion has taken place alongside concerns about citizen-state relations, the impact of mass surveillance on the behaviour of the surveyed (and the surveyor), the erosion of privacy and the perceived threat to civil liberties and human rights. Despite these concerns, and others that relate to the efficacy and financial implications of mass video surveillance, surveillance cameras and systems enjoy a degree of popularity amongst politicians, practitioners and the general public. Today, the presence of surveillance cameras and systems in many countries is taken for granted and their existence no longer feels 'revolutionary' they are just a normal part of everyday life. However, many of the concerns raised at the start of the revolution remain unanswered and are as pertinent today as they were in the 1990's.

The Special Issue places particular emphasis on studies of video surveillance in different national, institutional, cultural and linguistic settings, as they relate to the provision of these systems in public service and democratic contexts. Theoretically informed contributions from a variety of academic disciplines are employed, as are comparative and case studies. Whilst current academic debates on CCTV are heavily influenced by Anglophone literatures and examples, one of the central aims of this Special Issue is to bring together a more international collection of authors and studies and to provide insights into the modalities and developments of CCTV in a range of national and linguistic contexts. This approach will help to elucidate specific national and institutional characteristics, but also to highlight broader cross-cultural trends in current CCTV developments and policies. On this basis, we hope to develop a more solid, empirically informed understanding of the position and role of video surveillance in modern society, and of its governance and public-policy dimensions.

The 'Call for Papers' for this Special Issue brought forth a large number of submissions. From among these, over a dozen contributions are published in the two parts that make up the Special Issue (Volume 16, Nunber 4 and Volume 17, Number 1). Part One, presented here, consists of four articles and two case studies, providing insights in recent CCTV developments and policy debates in England, Catalonia, Sweden, France and Italy. Two book reviews complete these studies and reflections.

The first article, by Emmeline Taylor, entitled 'Awareness, Understanding and Experiences of CCTV Amongst Teachers and Pupils in Three UK Schools', examines the use of video surveillance cameras in the setting of schools in England. She explores, through new empirical research, the experiences of CCTV amongst teachers and pupils, and demonstrates how schools have become some of the most surveillanceintensive environments in modern society. The article raises important issues about the policy processes which have led to so much surveillance in this setting, the governance of CCTV in school settings and the long-term implications of exposing children to such intensive surveillance practices. The second article, by Gemma Galdon Clavell and entitled 'Local Surveillance in a Global World: Zooming in on the Proliferation of CCTV in Catalonia', explores the diffusion of CCTV in a specific region of Spain: Catalonia. The main thrust of her argument is that the specific context of Catalonian institutions and decision-making structures has shaped the provision of CCTV locally, and that common assumptions about national governments shaping CCTV diffusion are not borne out in Spain. In this respect, she asks us to 'zoom in' and pay attention to local decision-makers, politicians and service providers as they influence the diffusion process as well. 
Christoph Musik's article, 'The Thinking Eye is Only Half the Story: High-level Semantic Video Surveillance', looks at the evolution of the technological capabilities of surveillance systems, especially in relation to the need to interpret video images quickly and accurately. Two case studies are examined in detail - 'facial expression recognition' and 'automated multi-camera event recognition for the prevention of bank robberies' - through which he demonstrates how the computerization of video surveillance is leading to a 'second generation' of 'intelligent' systems. As Musik notes, 'the thinking eye is only half the story' and such developments raise issues about the design of these systems and who shapes their intelligence, and consequently their use. In the fourth article, 'Pure Flour in Your Bag: Governmental Rationalities of Camera Surveillance in Sweden', Fredrika Björklund utilises analytical approaches emerging from 'governmentality' perspectives to analyse critically the diffusion of video surveillance cameras in Sweden. Particular emphasis is placed upon 'situational prevention', the 'generalisation of distrust' and the 'informed citizen', through which she argues that Swedish society is undergoing an evolution that involves the blurring of traditional institutions and practices, and new ways of governing shaped by global pressures and technologies like video surveillance cameras. 'Pure flour in you bag' refers to an argument brought forward by those who advocate video surveillance and relates to those citizens who are 'whiter than white' and have nothing to fear from surveillance cameras.

Following on from the four main articles are two case studies. These are shorter pieces, rather less theoretical and a little more descriptive, but which nevertheless offer important insights for the governance of video surveillance cameras. In Part One of this Special Issue, we have accounts of the diffusion of video surveillance cameras in France and Italy. In the first case study, 'Video Surveillance and Security Policy in France: From Regulation to Widespread Acceptance', Eric Heilmann presents a historical account of the introduction and use of video surveillance cameras in France, with specific reference to the introduction of regulatory and legislative arrangements. He highlights the traditional tension between central and local government in France, how this has influenced the provision of video surveillance cameras, and the significance of political rhetoric to the continuing installation and operation of video surveillance cameras. The essence of Heilmann's argument is that France has changed from a country that resisted video surveillance to a country where it is widely accepted. In the second case study, 'The Silent Growth of Video Surveillance in Italy', Chiara Fonio analyses the diffusion of video surveillance in Italy with specific reference to the legislative framework and political processes. In particular, she points to discrepencies in regulatory requirements and the practices associated with video surveillance and the lack of a solid evidence base influencing the use of these technologies. For Fonio, the silence surrounding the growth of video surveillance in Italy relates to a lack of public debate and an apparent unwillingness to evaluate robustly the use and impacts of these technologies.

Part One finishes with reviews of two books that are related to privacy as a right that is affected by surveillance. Both books consider different aspects of privacy, and both reviews offer interesting insights about the governance of privacy. The first review, by Karl Löfgren, is of Colin J. Bennett's (2008) 'The Privacy Advocates: Resisting the Spread of Surveillance'. Here, Löfgren argues that this book makes an excellent contribution to the otherwise meagre political science tradition of studying privacy-related issues and that the book offers a first hand account of how those who advocate privacy - the privacy advocates - go about their business with the intention of making privacy a more central concern in policymaking processes. The second review, by Rocco Bellanova, is of Helen Nissenbaum's (2009) 'Privacy in Context: Technology, Policy and the Integrity of Social Life'. Bellanova's impassioned review argues that this book will be a seminal work for scholars dealing with privacy issues. In particular, he highlights the value of Nissenbaum's theory of privacy as 'contextual integrity' as a useful tool for reinvigorating contemporary debates about privacy. From both these book reviews, it is evident that conceptualizing and governing privacy remains a highly challenging and contested activity. 
Finally, we would like to thank the 'supporting cast' who have allowed us to bring this Special Issue to fruition. Firstly, thanks are due to the Editor-in-Chief of Information Polity for the opportunity to dedicate a double Special Issue to the topic of video surveillance. This has been a very timely exercise, one which has drawn together a variety of contemporary thinking on this topic. We would also like to thank the team at IOS Press for their support and patience whilst the editing was brought to conclusion. We are particularly grateful to all those reviewers who gave up their time to undertake the crucial role of peer-review, and to Joy Charnley who completed the translation, from French into English, of Eric Heilmann's case study. Finally, special thanks are due to all the authors who have contributed so many thought-provoking pieces on this topic area. Combined, they represent an impressive collection of contemporary theoretical and empirical work taking different perspectives on the surveillance camera revolution.

Editors:

Dr. C. William R. Webster Stirling Management School

University of Stirling

E-mail: c.w.r.webster@stir.ac.uk

Eric Töpfer

Centre for Technology and Society

Technische Universität Berlin

E-mail: toepfer@emato.de

Dr. Francisco R. Klauser Institute of Geography

University of Neuchâtel

E-mail: francisco.klauser@unine.ch

Professor Charles D. Raab

School of Social and Political Science

University of Edinburgh

E-mail: c.d.raab@ed.ac.uk 